\title{
ERRATUM
}

\section{Erratum to: Cloning and expression analysis of phytoene desaturase and $\zeta$-carotene desaturase genes in Carica papaya}

\author{
P. Yan $\cdot$ X. Z. Gao $\cdot$ W. T. Shen $\cdot$ P. Zhou
}

Published online: 24 July 2012

(C) Springer Science+Business Media B.V. 2012

Erratum to: Mol Biol Rep (2011) 38:785-791

DOI 10.1007/s11033-010-0167-2

"P. Yan and X. Z. Gao contributed equally to this work" is inappropriate and the appropriate statement is " $\mathrm{P}$. Yan and X. Z. Gao were the joint first authors and contributed equally to this work".

The online version of the original article can be found under doi:10.1007/s11033-010-0167-2.

P. Yan · X. Z. Gao · W. T. Shen · P. Zhou $(\bowtie)$

Key Laboratory of Tropical Crop Biotechnology, Ministry of Agriculture, Institute of Tropical Bioscience and

Biotechnology, Chinese Academy of Tropical Agricultural

Science, Haikou 571101, China

e-mail: zhp6301@126.com

\section{Z. Gao}

Department of Basic Medical Science, Hainan Medical College, Haikou 571101, China

P. Zhou

Analysis and Testing Center, Chinese Academy of Tropical

Agricultural Science, Haikou 571101, China 